\title{
PENGARUH PROGRAM "YUK NABUNG SAHAM" TERHADAP MINAT INVESTASI PADA KELOMPOK UKM DI KOTA PRABUMULIH SUMATERA SELATAN
}

\author{
THE EFFECT OF THE YUK NABUNG SAHAM PROGRAM ON INVESTMENT \\ INVESTMENT IN SME GROUP IN PRABUMULIH CITY, SOUTH SUMATERA
}

\author{
Zakaria Harahap \\ STIlE Prabumulih \\ zakariaharahap888@gmail.com
}

\begin{abstract}
Let's Save Stocks Against Investment Interest in SMEs Group in Prabumulih City, South Sumatra. The purpose of this study is to analyze the impact of the "Yuk Nabung Saham" program on investment interest in the SME group in Prabumulih City, South Sumatra. The research method used in this study using a survey method. By collecting primary data and secondary data. The selection of the research location was determined deliberately (purposive sampling) then the data obtained would be analyzed using the $T$ test with simple linear regression. The population selection in this study was the UKM group in Prabumulih as many as 5,436 UKM, the method of determining the sample used was purposive sampling with the consideration of respondents who were influencers / deciders, with sampling using the Slovin Umar formula (2013), so the sample to be used in this study is as many as 98 respondents representing a randomly selected population. The results show that the value of the correlation coefficient and the coefficient of determination can be used to determine the proportion of the independent variables $(X)$ in explaining the $Y$ variable.The correlation coefficient of 0.827 indicates that there is a strong and unidirectional influence between saving stocks and investment interest in the Prabumulih City UKM group. . The coefficient of determination is 0.827 or $82.7 \%$, the variation of saving stocks, which can explain the investment interest variable, while the remaining $13.7 \%$ is explained by other variables not examined in this study.
\end{abstract}

Keywords: Saving Stocks and Investment Interest

\begin{abstract}
ABSTRAK
Yuk Nabung Saham Terhadap Minat Investasi Pada Kelompok Ukm Di Kota Prabumulih Sumatera Selatan. Tujuan dari penelitian ini untuk menganalisa dampak program "Yuk Nabung Saham" terhadap minat investasi pada kelompok UKM di Kota Prabumulih Sumatera Selatan. Metode penelitian yang digunakan dalam penelitian ini dengan menggunakan metode survey. Dengan mengumpulkan data primer dan data skunder. Pemilihan lokasi penelitian ditentukan dengan sengaja (Purposive Sampling) selanjutnya data yang diperoleh akan dianalisa menggunakan Uji T dengan Regresi Linear Sederhana. Pemilihan populasi dalam penelitian ini yaitu kelompok UKM di Prabumulih sebanyak 5.436 UKM, metode penentuan sampel yang digunakan adalah purposive sampling dengan pertimbangan responden yang merupakan influencer/
\end{abstract}


decider, dengan penarikan sampel menggunakan rumus Slovin Umar (2013), jadi sampel yang akan digunakan dalam penelitian ini adalah sebanyak 98 responden yang mewakili populasi yang diplih secara acak. Hasil penelitian menunjukkan nilai dari koefisien korelasi dan koefisien determinasi dapat digunakan untuk mengetahui besarnya proporsi variable-variabel independen $(\mathrm{X})$ dalam menjelaskan variabel $\mathrm{Y}$. Koefisien korelasi sebesar 0,827 menandakan bahwa terdapat pengaruh yang kuat dan searah antara nabung saham dengan minat investasi kelompok UKM Kota Prabumulih. Koefisien determinasi sebesar 0,827 atau $82,7 \%$ variasi dari nabung saham yaitu dapat menjelaskan variabel minat investasi sedang sisanya $13,7 \%$ lagi dijelaskan oleh variabel lain yang tidak diteliti dalam penelitian ini.

Kata Kunci: Nabung Saham dan Minat Investasi

\section{PENDAHULUAN}

Bursa Indonesia merupakan yang terbesar di dunia namun selama 10 tahun terakhir yang menikamati justru investor asing dibanding lokal dengan perbandingan 70:30 (Vilta \& Kafabih 205). Fluktuasi harga Indeks Harga Saham Gabungan (IHSG) di Bursa Efek Indonesia (BEI) masih dikuasai asing dan belum menjadi tuan rumah di negeri sendiri, tidak heran jika investor asing melakukan aksi penjualan besarbesaran maka dapat dipastikan IHSG di BEI akan merah dan mengalami penurunan. Hal ini tentunya berdampak pada iklim investasi dan pertumbuhan ekonomi nasional (Wahyuningsih 2015).

Investasi sudah dikenal oleh masyarakat Kota Prabumulih Sumatera Selatan sudah sejak lama. Namun bentuk investaasi masih dalam bentuk konvensional. Bagi masyarakat Kota Prabumulih sektor pertanian merupakan sumber mata pencarian utama. Secara umum masyarakat mengenal investasi dengan 2 cara yaitu membeli emas perhiasan dan membeli tanah perkebunan baik kebun karet atau kebun sawit. Jika ada kebutuhan musiman seperti musim anak masuk sekolah atau kuliah dan hari-hari besar seperti Lebaran atau hajatan seperti pernikahan maka beramai-ramai masyarakat menjual emas untuk memenuhi kebutuhannya atau menjual kebun sebagai bentuk investasi jangka panjang.

Tujuan dari penelitian ini untuk menganalisa dampak program "Yuk Nabung Saham" terhadap minat investasi pada kelompok UKM di Kota Prabumulih Sumatera Selatan. Metode penelitian yang digunakan dalam penelitian ini dengan menggunakan metode survey. Dengan mengumpulkan data primer dan data skunder. Pemilihan lokasi penelitian ditentukan dengan sengaja (Purposive Sampling) selanjutnya data yang diperoleh akan dianalisa menggunakan uji instrumen, Uji t dengan Regresi Linear Sederhana.

Minat adalah sesuatu yang pribadi dan berhubungan dengan sikap, individu yang berminat terhadap suatu obyek akan mempunyai kekuatan atau dorongan untuk melakukan serangkaian tingkah laku untuk mendekati atau mendapatkan objek tertentu, Minat merupakan rasa lebih menyukai atau suatu rasa tertarik terhadap perihal atau kegiatan, tanpa ada yang memberikan suruhan (hendarsono 2013). Minat dapat didefinisikan sebagai suatu kecenderungan dari hati yang tinggi terhadap suatu keinginan atau tujuan (KBBI). Minat investasi merupakan suatu keinginan untuk menempatkan sebagian dananya pada pasar modal dengan maksud mendapatkan 
keuntungan di masa depan (Manggu 2018).

Masyarakat Indonesia belum sepenuhnya menginvestasikan dananya ke pasar modal dengan pertimbangan tertentu. Bursa Efek Indonesia (BEI), Lembaga Kliring dan Penjaminan (KPEI) dan PT Kustodian Sentral Efek Indonesia (KSEI) sebagai fasilitator pasar modal Indonesia berusaha agar jumlah investor Indonesia meningkat dengan berbagai cara, misalnya dengan iklan dan membuat sebuah konsep industri pasar modal yang kuat dan berskala nasional dengan tujuan untuk meningkatkan kesadaran terhadap pasar modal Indonesia, kampanye investasi tersebut bernama "Yuk Nabung Saham" (yuknabungsaham.idx.co.id)

Kampanye tersebut bertujuan untuk mengajak masyarakat indonesia untuk menginvestasikan dananya dengan membeli suatu saham secara berkala dan rutin di pasar modal serta memberikan kesadaran akan investasi yang sangat berguna untuk masa depan. Di samping itu juga untuk memberikan pengetahuan terkait dengan seluk beluk investasi di pasar modal.

\section{METODE PENELITIAN}

\section{Desain Penelitian}

Penelitian ini menggunakan pendekatan kuantitatif, pengumpulan data primer menggunakan metode survei. Survei merupakan proses pengukuran yang digunakan untuk mengumpulkan data dengan menggunakan kuesioner. Penelitian ini dimulai dengan hipotesis dan melibatkan prosedur yang tepat dengan sumber data spesifik karena itu penelitian ini termasuk dalam confirmatory reseach. Dilihat dari dimensi waktu, penelitian ini tergolong dalam cross sectional study karena dilakukan hanya sekali pada satu waktu.

\section{Jenis Penelitian}

Kajian ini menggunakan metode penelitian konklusif kausal, dimana jenis penelitian kausal adalah jenis riset yang memiliki maksud utama ialah menemukan bukti terkait hubungan sebab-akibat. Untuk mendukung jenis riset kausal, maka dalam kajian ini digunakan data yang kuantitatif dan sumber data primer.

\section{Populasi dan Sampel}

Pemilih populasi dalam penelitian ini yaitu UKM di Prabumulih sebanyak 5.436 UKM, metode penentuan sampel yang digunakan adalah purposive sampling dengan pertimbangan responden yang merupakan influencer/ decider. dengan penarikan sampel menggunakan rumus Slovin. Jadi sampel yang akan digunakan dalam penelitian ini adalah sebanyak 98 responden yang mewakili populasi yang diplih secara acak. Karena populasi bersifat homogeny maka 98 sampel sudah cukup mewakili populasi. Populasi 98 sampel didapat dengan menggunakan rumus slovin

\section{Sumber dan Jenis Data}

Sumber Data terdiri atas data primer dan data sekunder. Data primer, diperoleh dari responden melalui kuesioner, sedangkan data sekunder, dalam penelitian ini adalah data mengenai kelompok UKM yang ada di Prabumulih.

Jenis data yang digunakan adalah data kuantitatif, data kuantitatif adalah data yang berupa angka-angka (Qomari 2010). Dalam penelitian ini data kuantitatif berupa jumlah responden dan hasil survei yang sudah dikuantitatifkan dengan skala likert. Sedangkan data kualitatif adalah data yang tidak berbentuk angka. Data 
kualitatif dalam penelitian ini adalah demografis responden.

\section{Metode Pengumpulan Data}

Metode pengumpulan data yang digunakan dalam penelitian ini adalah: (1) Observasi, yaitu dengan pengamatan langsung untuk mendukung data yang diperlukan, misal mengamati responden kelompok UKM Kota Prabumulih; (2) Kuesioner, yaitu pengumpulan data yang dilakukan dengan penyebaran kuesioner atau daftar pertanyaan yang berhubungan dengan penelitian ini kepada responden untuk memperoleh data berupa jawaban-jawaban dari para responden. Kuesioner dalam penelitian ini diukur dalam skala likert 5 mulai dari sangat setuju, setuju, netral, tidak setuju dan sangat tidak setuju; (3) Metode wawancara, yaitu pengumpulan data dengan menanyai langsung diluar kuesioner, misal sebelum kuesioner diberikan kepada calon respoden, calon respoden diwawancarai terlebih dahulu tentang apakah mereka sudah atau belum ikut investasi saham, sehingga sampel yang diteliti tepat.

\section{Metode Pengolahan dan Analisis Data}

Data yang diperoleh akan dianalisis dengan menggunakan data kualitatif dan kuantitatif. Data kualitatif disajikan dalam uraian atau deskriptif, sedangkan data kuantitatif akan disajikan dalam bentuk tabulasi. Menurut Nazir (2014), analisis deskriptif adalah suatu metode dalam meneliti status kelompok manusia, suatu objek, suatu sistem pemikiran ataupun suatu kelas peristiwa pada masa sekarang. Analisis deskriptif digunakan untuk mengetahui karakteristik setiap variabel dalam sampel.

Teknik analisis regresi yang digunakan dalam penelitian ini adalah Regresi Linier Sederhana. Berdasarkan tujuan dilakukannya penelitian ini, maka variabel yang dianalisis adalah variabel independen yaitu Nabung Saham (variabel X) dan Minat Investasi (variabel Y), data hasil tabulasi diterapkan pada pendekatan penelitian yaitu dengan analisis regresi. Persamaan regrasi sederhana $\mathrm{X}$ atas $\mathrm{Y}$, adalah sebagai berikut:

$$
\mathrm{Y}=\mathrm{a}+\mathrm{bX}+\mathrm{e}
$$

\section{HASIL DAN PEMBAHASAN Hasil Analisis Data}

Untuk mengetahui bahwa instrument dalam penelitian ini merupakan alat ukur yang akurat dan dapat dipercaya maka diperlukan pengujian data. Pengujian data yang digunakan meliputi uji validitas dan uji reliabilitas. Untuk melakukan uji validitas dan reliabilitas, penulis menggunakan program SPSS For Windows. Variabel yang diuji adalah variabel bebas (Independen) yaitu nabung saham dan variabel dependen minat investasi.

Analisis regresi linier digunakan untuk membuktikan sejauh mana pengaruh nabung saham terhadap minat investasi, maka dapat digunakan analisis regresi dengan menggunakan bantuan program SPSS yang hasilnya dapat dilihat melalui tabel berikut ini :

Tabel 1 Hasil Uji Regresi

\begin{tabular}{|c|c|c|c|c|c|c|}
\hline & & \multicolumn{2}{|c|}{$\begin{array}{l}\text { Unstandardized } \\
\text { Coefficients }\end{array}$} & $\begin{array}{l}\text { Standardized } \\
\text { Coefficients }\end{array}$ & $\mathrm{t}$ & Sig. \\
\hline \multicolumn{2}{|c|}{ Model } & B & Std. Error & Beta & & \\
\hline \multirow[t]{2}{*}{1} & ista & 34.212 & 12.798 & & 4.275 & .000 \\
\hline & $\begin{array}{l}\text { Nabung } \\
\text { saham } \\
(\mathrm{X})\end{array}$ & .615 & .753 & .642 & 2.780 & .003 \\
\hline \multicolumn{7}{|c|}{$\begin{array}{l}\text { a. Dependent Variable: Minat } \\
\text { investasi }(Y)\end{array}$} \\
\hline \multicolumn{7}{|c|}{$\begin{array}{l}\text { Untuk melihat berapa besar } \\
\text { pengaruh nabung saham terhadap minat } \\
\text { investasi, maka }\end{array}$} \\
\hline
\end{tabular}


Dalam kaitannya dengan uraian tersebut di atas, maka dapat disajikan interprestasi sebagai berikut::

1. Nilai koefisien regresi $b_{0}=34,212$ dengan tanda positif yang merupakan nilai konstanta dimana diartikan bahwa jika variabelvariabel independen yaitu nabung saham diasumsikan dengan nilai konstan, maka variabel dependen yaitu minat investasi akan naik sebesar 34,212\%.

2. Nilai koefisien regresi $X$ (b1) sebesar 0,615 artinya untuk setiap kenaikan 1 skor variabel nabung saham (X) akan menaikkan skor minat investasi $(\mathrm{Y})$ sebesar 0,615 .

\section{Uji Hipotesis}

Pengujian hipotesis akan dilakukan dengan tiga uji yaitu uji $\mathrm{t}$ (secara parsial), Uji Koefisien Determinasi (Adjusted $R$ Square) dengan prosedur pengujiannya sebagai berikut :

Tabel 2 Hasil Uji t

\begin{tabular}{|c|c|c|c|c|c|c|}
\hline \multirow{2}{*}{\multicolumn{2}{|c|}{ Model }} & \multicolumn{2}{|c|}{$\begin{array}{c}\text { Unstandardized } \\
\text { Coefficients }\end{array}$} & \multirow{2}{*}{$\begin{array}{c}\begin{array}{c}\text { Standardiz } \\
\text { ed } \\
\text { Coefficient } \\
\mathrm{s}\end{array} \\
\text { Beta } \\
\end{array}$} & \multirow[t]{2}{*}{$\mathrm{t}$} & \multirow[t]{2}{*}{ Sig. } \\
\hline & & B & Std. Error & & & \\
\hline \multirow[t]{2}{*}{1} & (Constant) & 34.212 & 12.798 & & 4.275 & .000 \\
\hline & $\begin{array}{l}\text { Nabung } \\
\text { saham (X) }\end{array}$ & .615 & .753 & .642 & 2.780 & .003 \\
\hline
\end{tabular}

\section{Uji t (secara parsial)}

Uji parsial dimaksudkan dengan membandingkan $t_{\text {hitung }}$ dan tabel untuk variabel nabung saham terhadap minat investasi, dimana diperoleh bahwa:

$\mathrm{H} 0=$ Koefisien regresi tidak signifikan $\mathrm{Ha}=$ Koefisien regresi signifikan

Pengambilan keputusan berdasarkan probabilitas, Jika Probabilitas $>0,05 \mathrm{H} 0$ diterima, Jika Probabilitas $<0,05$ H0 ditolak. Dari hasil koefisien regresi maka diperoleh koefisien regresi sebesar 0,615 , selain itu memiliki nilai $t_{\text {hitung nabung saham }}$ sebesar 2,780 dan $t_{\text {tabel }} 1,985$, serta memiliki nilai probabilitas $0,000<0,05$. Karena nilai thitung lebih besar dari tabel serta memiliki nilai probabilitas yang lebih kecil dari nilai standar, maka dapat dikatakan bahwa nabung saham mempunyai pengaruh yang signifikan terhadap minat investasi kelompok UKM Kota Prabumulih.

\section{Koefisien Determinan}

Analisis koefisien determinasi digunakan untuk melihat seberapa besar variabel independen berpengaruh terhadap variabel dependen yang dinyatakan dalam persentase. Berdasarkan hasil pengolahan data dengan menggunakan bantuan program SPSS For Windows diperoleh hasil sebagai berikut :

Tabel 3Koefisien Determinasi

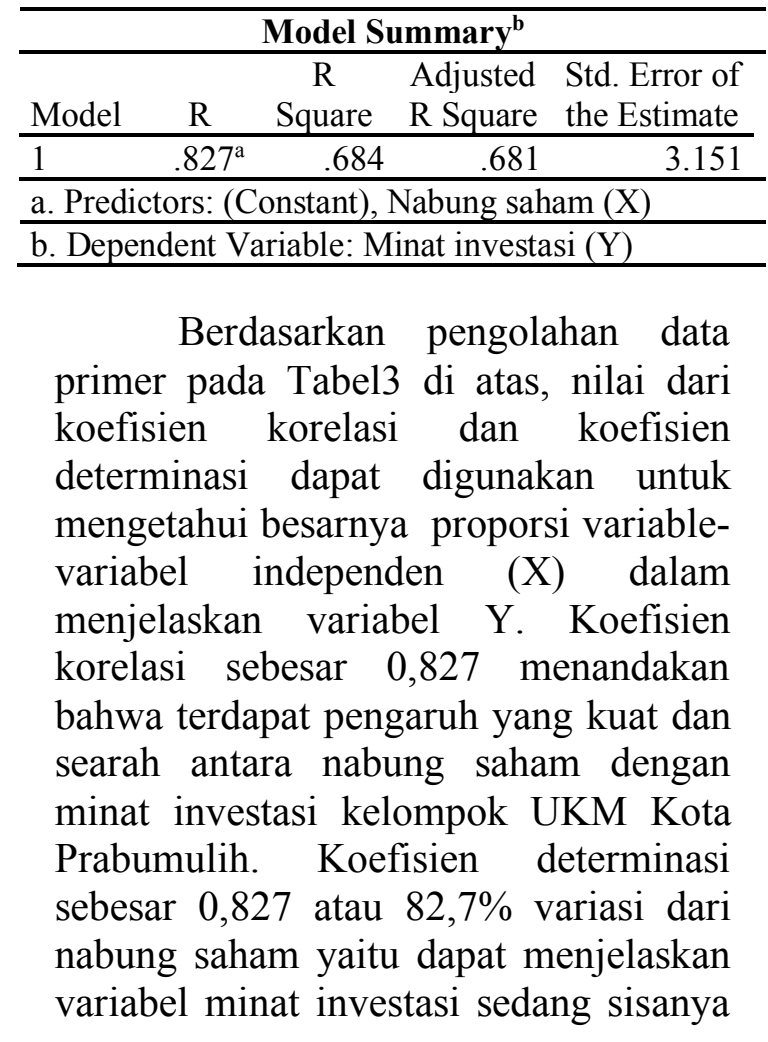


$13,7 \%$ lagi dijelaskan oleh variabel lain yang tidak diteliti dalam penelitian ini.

Melalui hasil penelitian ini, maka sebaiknya di Kota Prabumulih didirikan galeri investasi baik untuk kelompok UKM maupun bagi mahasiswa. Penelitian Purboyo (2020) menunjukkan pentingnya aktivitas galeri investasi bagi mendukung minat untuk berinvestasi.

\section{PENUTUP}

\section{Kesimpulan}

Penelitian ini bertujuan untuk mengetahui pengaruh nabung saham terhadap minat berinvestasi pada kelompok UKM Kota Prabumulih. Dari rumusan masalah yang diajukan, maka analisis data yang telah dilakukan dan pembahasan yang telah dikemukakan pada bab sebelumnya, dapat ditarik kesimpulan sebagai berikut :

1. Variabel nabung saham berpengaruh secara signifikan terhadap minat berinvestasi pada kelompok UKM Kota Prabumulih. Hasil pengujian dalam penelitian ini menunjukkan nilai $\mathrm{T}$ sebesar 2.780 , dan memiliki nilai $t_{\text {hitung }}$ nabung saham sebesar 2.780 dan tabel 1.985 , serta memiliki nilai probabilitas $0,000<0,05$. Karena nilai $t_{\text {hitung }}$ lebih besar dari $t_{\text {tabel }}$ serta memiliki nilai probabilitas yang lebih kecil dari nilai standar, maka dapat dikatakan bahwa nabung saham mempunyai pengaruh yang signifikan terhadap minat investasi kelompok UKM Kota Prabumulih.

2. Koefisien korelasi sebesar 0,762 menandakan bahwa terdapat pengaruh yang kuat dan searah antara nabung saham dengan minat investasi kelompok UKM Kota Prabumulih. Koefisien determinasi sebesar 0,827 atau $82,7 \%$ variasi dari nabung saham artinya variabel nabung saham dapat menjelaskan variabel minat investasi, sebesar
$82,7 \%$ sedang sisanya $17,3 \%$ dijelaskan oleh faktor-faktor lain yang tidak diteliti dalam penelitian ini.

\section{Saran}

Adapun saran-saran yang penulis ajukan berdasarkan hasil penelitian ini saran-saran sebagai berikut :

1. Bagi Galeri Investasi:

Sebaiknya di Kota Prabumulih didirikan galeri investasi baik untuk kelompok UKM maupun bagi mahasiswa. Pengurus Galeri Investasi agar meningkatkan kinerja investasi sehingga peserta kelompok UKM dan juga mahasiswa dapat memperoleh keuntungan dari tabungan jangka panjang, dan menantang diri sendiri dalam berusaha mengatur keuangan mereka dikarenakan menurut hasil penelitian variabel nabung saham tersebut dapat mempengaruhi upaya dalam meningkatkan jumlah anggota Galeri Investasi terhadap minat investasi saham.

2. Bagi Penelitian Selanjutnya

Bagi peneliti yang ak an melakukan penelitian lebih lanjut diharapkan penelitian ini menjadi referensi tambahan, diharapkan agar menggunakan sampel yang lebih banyak sehingga hasil yang akan dihasilkan akan lebih meyakinkan. Dan pada penelitian ini lingkup respondennya hanya pada UKM, maka dari itu untuk peneliti selanjutnya dapat melakukan penelitian lebih lanjut pada tingkat mahasiswa sehingga dapat diketahui apakah terdapat perbedaan persepsi ketika masih menjadi mahasiswa dan ketika sudah berada di dunia kerja (alumni). 


\section{DAFTAR PUSTAKA}

Hendarsono, G. (2013). Analisa pengaruh Experiential marketing terhadap minat beli ulang konsumen cafe buntos 99 Sidoarjo. Jurnal Strategi Pemasaran, 1(2), 1-8.

Manggu, S. A. R. (2018). Pengaruh Pengetahuan, Persepsi Dan Preferensi Risiko Masyarakat Di Kabupaten Majene Terhadap Minat Berinvestasi Di Pasar Modal.

Purboyo, P., Zulfikar, R., \& Wicaksono, T. (2020). Pengaruh Aktifitas Galeri Investasi, Modal Minimal Investasi, Persepsi Resiko Dan Persepsi Return Terhadap Minat Investasi Saham Syariah (Studi pada Mahasiswa Uniska MAB Banjarmasin). JWM (Jurnal Wawasan Manajemen), 7(2), 136-150.

Qomari, R. (2009). Teknik penelusuran analisis data kuantitatif dalam penelitian kependidikan. INSANIA: Jurnal Pemikiran Alternatif Kependidikan, 14(3), 527-539.

Volta, G. D. M., \& Kafabih, F. (2015). Reformulasi Sistem Bagi Hasil Melalui Kontrak Bagi Produksi Guna Mewujudkan Kedaulatan Migas. Panggung Hukum, 1(1).

Wahyuningsih, T. (2012). Dampak investasi pemerintah dan investasi swasta terhadap pertumbuhan ekonomi dan kesejahteraan masyarakat di Provinsi Maluku. IQTISHODUN 